\title{
Correction to: Perfluorooctane sulfonate (PFOS) and perfluorooctanoic acid (PFOA) induce epigenetic alterations and promote human breast cell carcinogenesis in vitro
}

\author{
Paula Pierozan $^{1}$ [D $\cdot$ Daiane Cattani ${ }^{1} \cdot$ Oskar Karlsson $^{1}$
}

Published online: 13 August 2020

(c) The Author(s) 2020

\section{Correction to: Archives of Toxicology \\ https://doi.org/10.1007/s00204-020-02848-6}

The correct Fig. 2 is given in this correction.

The original article has been updated.

In the original publication of the article, Fig. 2 has been published with an error. An error bar has been introduced in Fig. 2 (panel B, second image to the right).

The original article can be found online at https://doi.org/10.1007/ s00204-020-02848-6.

Paula Pierozan

paula.pierozan@aces.su.se

1 Science for Life Laboratory, Department of Environmental Sciences, Stockholm University, 11418 Stockholm, Sweden 




b

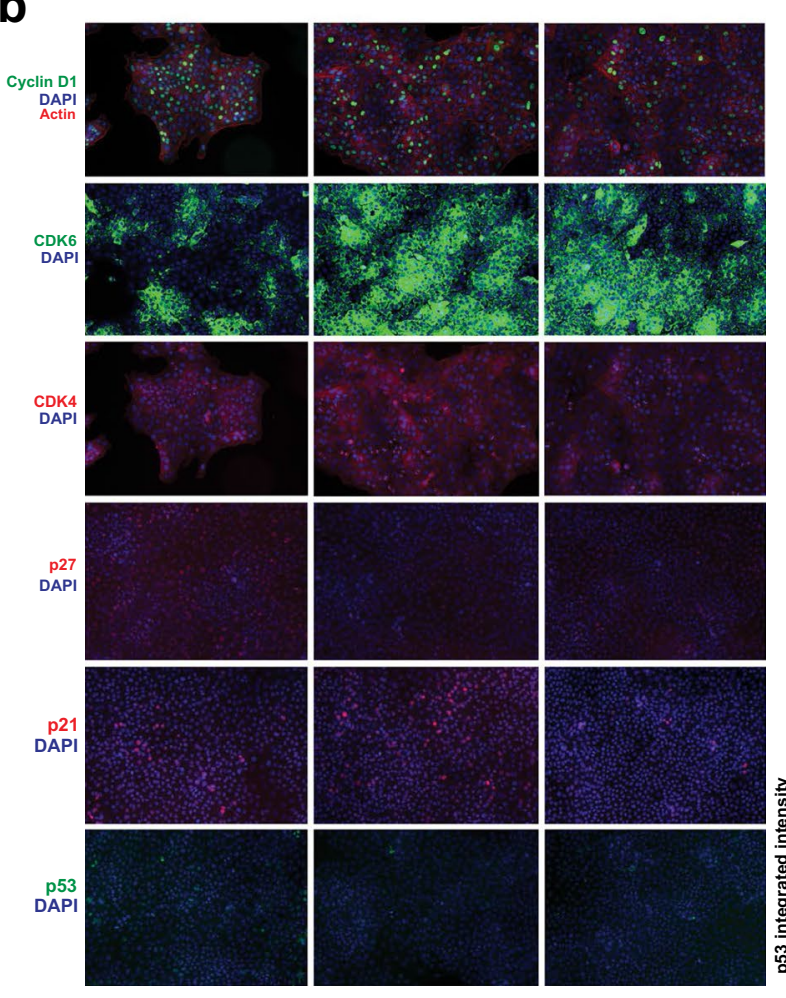

Fig. 2 Effects on regulatory cell-cycle proteins in daughter cells (D1 and D2) of MCF-10A cells exposed to PFOS $(10 \mu \mathrm{M})$ or PFOA $(100 \mu \mathrm{M})$. Representative images of D1 (a) and D2 (b) cells immunostained with Cyclin D1 and actin, CDK6, CDK4, p27, p21 and p53. Integrated fluorescence intensity (c-d and $\mathbf{g}-\mathbf{p})$ and nuclear


m
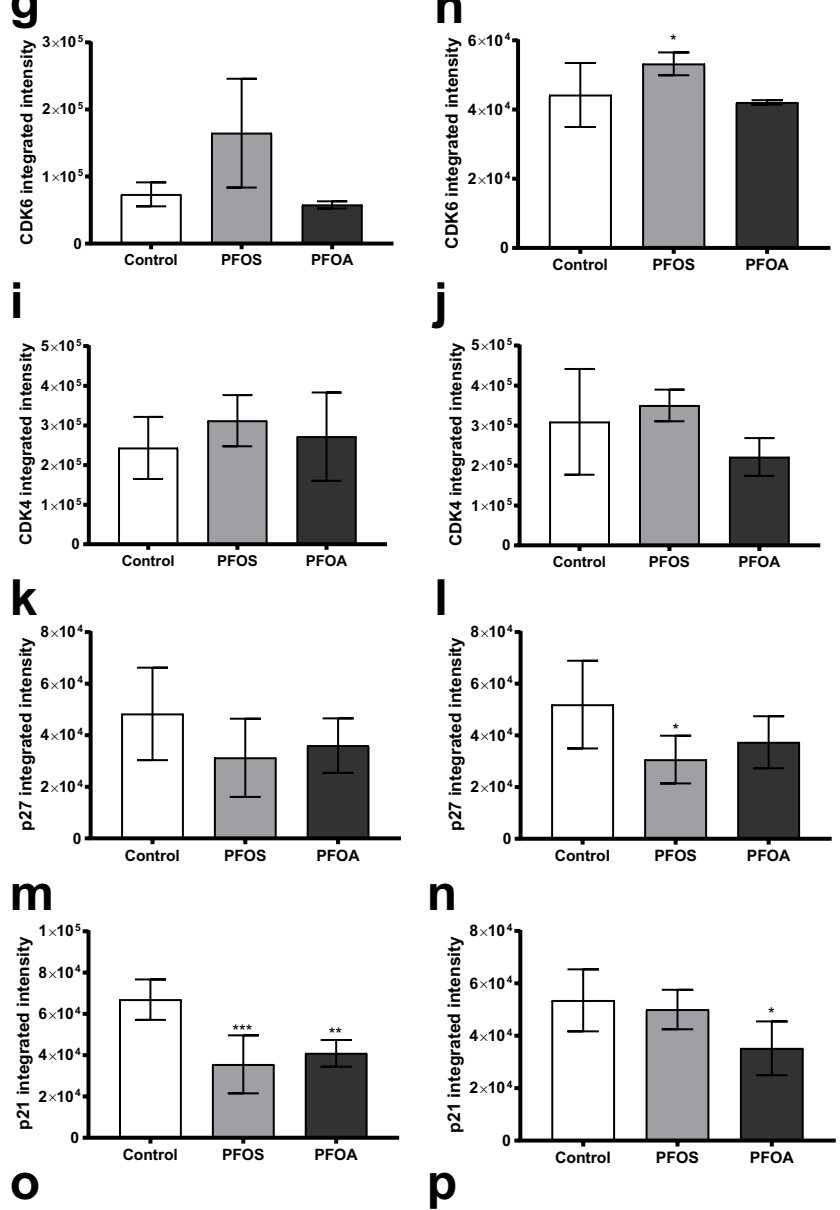

n
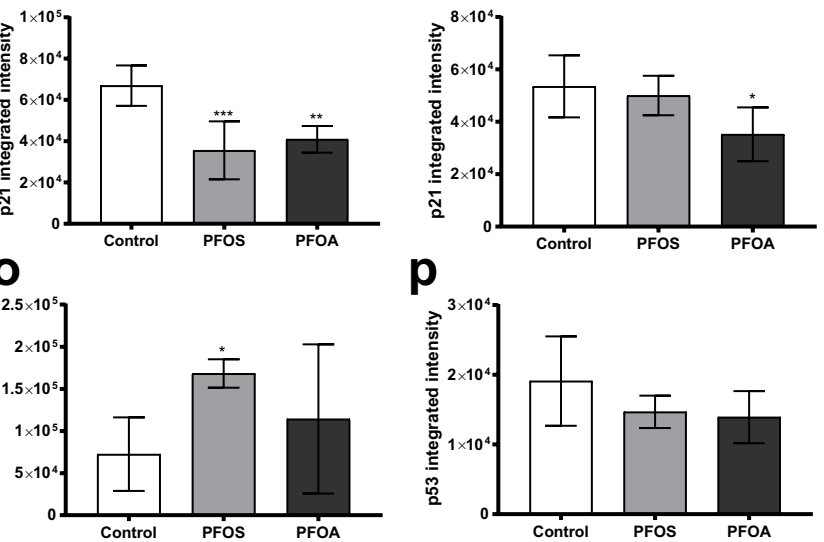

cyclin D1 levels $(\mathbf{e}, \mathbf{f})$ were analyzed as described in Materials and methods. Values represent mean \pm SD from three independent experiments. Statistically significant differences from control are indicated as follows: $* p<0.05, * * p<0.01$ and $* * * p<0.001$ (One-Way ANOVA followed by the Tukey-Kramer test). Scale bar $=50 \mu \mathrm{m}$ 
Publisher's Note Springer Nature remains neutral with regard to jurisdictional claims in published maps and institutional affiliations. 